\title{
Osteonecrosis and Antiphospholipid Antibodies
}

\author{
Savino Sciascia and Maria Tiziana Bertero
}

Key words: osteonecrosis, antiphospholipid antibodies

(Inter Med 48: 737-738, 2009)

(DOI: 10.2169/internalmedicine.48.2063)

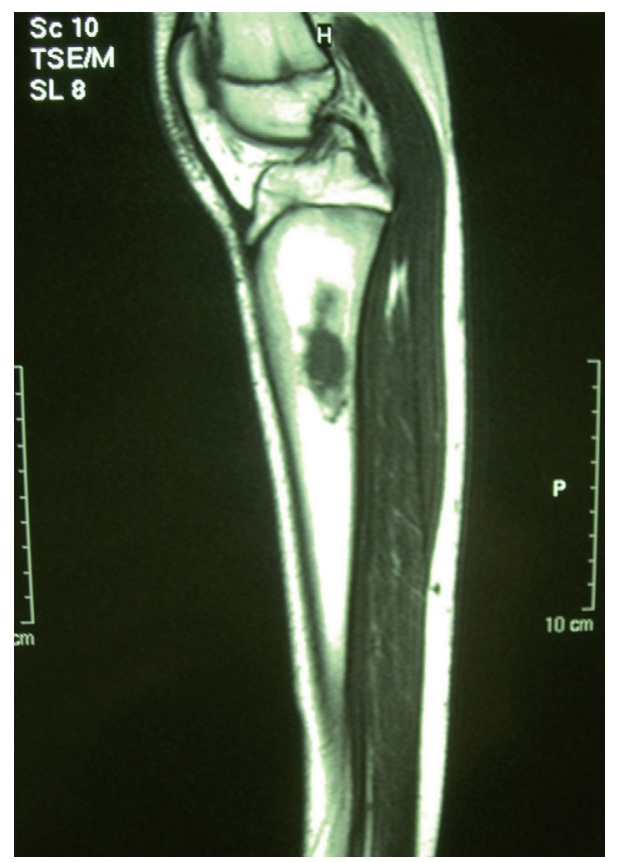

Picture 1. Magnetic resonance imaging (MRI) showed extensive bone lesion in proximal tibia at the right knee in a 15-year-old patient with high levels of antiphospholipid antibodies.

A 15-year-old Indian girl presented to our centre with a history of two episodes of bilateral chorea, explained as Sydenham's Chorea, and an intense pain at the lower limbs. Magnetic resonance imaging (MRI) showed extensive bone lesions in the distal femur and proximal tibia at the right knee (Picture 1). Tibia bone biopsy was consistent with osteonecrosis. Laboratory tests revealed persistently high levels of antiphospholipid antibodies (aPL) with no other immunological findings of a connective tissue disease. We hy- pothesize that bone lesions due to osteonecrosis may be correlated with antiphospholipid antibodies as microvascular occlusions (1). Corticosteroid use and other conditions associated with osteonecrosis were excluded. Such bone lesions could develop in aPL patients, although they are uncommon (2). No other events (thrombosis or fetal losses) suggestive of antiphospholipid syndrome occurred. Therapy with lowdose aspirin was given and MRI 1 year later showed a definite reduction of bone lesions.

\section{References}

1. Asherson RA, Cervera R. Microvascular and microangiopathic antiphospholipid-associated syndromes ("MAPS"): semantic or an- tisemantic? Autoimmun Rev 7: 164-167, 2008.

2. Gorshtein A, Levy Y. Orthopedic involvement in antiphospholipid

Allergy and Clinical Immunology Department, Umberto I Hospital, Turin, Italy

Received for publication January 16, 2009; Accepted for publication January 25, 2009

Correspondence to Dr. Savino Sciascia, savino.sciascia@alice.it 
Inter Med 48: 737-738, 2009 DOI: 10.2169/internalmedicine.48.2063

syndrome. Clin Rev Allergy Immunol 32: 167-171, 2007.

(C) 2009 The Japanese Society of Internal Medicine http://www.naika.or.jp/imindex.html 